\title{
Empirical Study Of The Relationship Between Leadership and Organizational Citizenship Behavior: A Literature Review
}

\author{
Muhdar HM; ${ }^{1}$ \\ muhdar73@gmail.com
}

\begin{abstract}
Abstrak
Banyak yang telah menulis teori kepemimpinan dan organizational citizenship behavior, bahkan mencoba menghubungkan antara keduanya dalam bentuk penelitian empiris. Hal ini menandakan bahwa pengembangan ilmu pengetahuan di bidang kepemimpinan dan organizational citizenship behavior terus berkembang hingga saat ini. Dalam lingkungan yang kompetitif yang tinggi saat ini, di mana organisasi mencari orangorang yang dapat membantu mereka dalam mencapai keunggulan kompetitif, orang-orang yang berperilaku OCB dapat membantu mereka. OCB penting bagi fungsi efektif dari sebuah organisasi karena tujuan utamanya adalah untuk membuat semua karyawan bekerja untuk mencapai tujuan organisasi dari menyelesaikan tugas-tugas mereka. Hal ini didefinisikan sebagai perilaku individu yang diskresioner. Diskresioner artinya perilaku individu yang bukan hanya melaksanakan perannya (in-role) tetapi juga diluar perannya (extra-role). Karena itu, perlu penerapan kepemimpinan yang efektif untuk memfungsikan OCB. Tujuan penulisan artikel ini adalah untuk mengkaji dan mendokumentasikan beberapa penelitian empiris hubungan antara kepemimpinan dengan organizational citizenship behavior. Dengan metode penulisan kajian literatur dari beberapa penelitian empirik ditemukan pengaruh positif yang signifikan gaya kepemimpinan terhadap organizational citizenship behavior. Gaya kepemimpinan seperti transformasional, transaksional, kharismatik, otoritas, etis dan melayani secara signifikan berpengaruh terhadap organizational citizenship behavior. Namun kepemimpinan trasformsional dan melayani tidak semua peneliti menemukan hasil yang sama. Hasil ini mengindikasikan semakin efektif kepemimpinan oleh pemimpin maka semakin baik OCB karyawan, akibatnya efektivitas dan produktivitas organisasi juga lebih baik.
\end{abstract}

Kata Kunci: Kepemimpinan, Organizational Citizenship Behavior.

\section{Pendahuluan}

Saat ini, peran pemimpin telah menjadi sangat diperlukan untuk pertumbuhan organisasi. Kepemimpinan telah dipelajari secara ekstensif dalam berbagai konteks dan dasar teori selama bertahun-tahun. Kepemimpinan adalah salah satu yang paling banyak dipelajari dan dicari tema dalam kehidupan organisasi. Kepemimpinan dipandang sebagai faktor penting dalam inisiasi dan implementasi transformasi dalam organisasi. Baik praktisi maupun peneliti berpendapat jika kepemimpinan ingin merangsang dampak afirmatif pada individu, tim, dan organisasi, maka paradigma kepemimpinan sebelumnya seperti kepemimpinan direktif versus kepemimpinan partisipatif, pertimbangan versus struktur inisiasi, otokratis versus demokratis, dan tugas versus berorientasi pada hubungan yang diperluas. Sehubungan dengan pengelolaan proses transformasi dalam organisasi, ada kebutuhan yang kuat bagi para pemimpin yang lebih banyak pada pusat perubahan. Para pemimpin ini menempatkan nilai pada pengembangan visi yang jelas dan menginspirasi pengikutnya untuk mengejar visi.

${ }^{1}$ Lecturer at Faculty of Economics and Islamic Business, State Islamic Institute of Sultan Amai Gorontalo, Indonesia 
Dengan cara ini, mereka memberikan kekuatan motivasi yang kuat untuk perubahan dalam diri bawahan mereka.

Beberapa peneliti yang dikutip oleh Lee Kim Lian\& Low Guan Tui. (2012) menyarankan bahwa penelitian kepemimpinan perlu lebih fokus pada isu-isu "fundamental", seperti proses pengaruh yang mencirikan interaksi pemimpin-pengikut (Bass, 1990; Hollander \& Offermann, 1990; Yukl, 1989). Penelitian juga menunjukkan bahwa pemimpin yang efektif harus memiliki kemampuan untuk mengenali kapan harus menggunakan kepemimpinan yang berbeda dari pengaruh serta keterampilan yang diperlukan untuk secara efektif melaksanakan upaya pengaruh ini (Kipnis, et.al., 1980; Yukl \& Falbe, 1990; Yukl, 1998; Bolino \& Turnley, 2003). Pentingnya gaya kepemimpinan sebagai prediktor organizational citizenship behavior $(O C B)$ telah disetting dengan baik oleh dunia Barat (Bass, 1985; Organ, 1988; Podsakoff, et, al., 1990; Howell \& Avolio, 1993; Lowe, et.al., 1996; Podsakoff, et, al., 1996; MacKenzie, et.al., 2001; Geyer \& Steyrer, 1998; Wang, et, al., 2005; Schlechter \& Engelbrecht, 2006; Boerner, et.al., 2007) ${ }^{2}$

Sisi lain, ada juga studi tentang OCB seputar isu hubungan interpersonal yang telah didorong oleh keyakinan bahwa hubungan atasan-bawahan sangat penting untuk keberhasilan organisasi. Hubungan interpersonal di tempat kerja harus meningkatkan OCB secara positif antara karyawan. Bawahan dengan tingkat OCB yang tinggi lebih cenderung berkomitmen terhadap organisasi (William \& Anderson, 1991; Smith, Organ \& Near, 1983). Oleh karena itu, akan lebih superior kegunaannya bagi gaya kepemimpinan yang sadar dalam situasi kerja dan bagaimana mempromosikan OCB bawahan. Graham (1988) dan Podsakoff, MacKenzie, Moorman dan Fetter (1990) telah menunjukkan bahwa gaya kepemimpinan dan OCB bawahan saling berkaitan. Gaya kepemimpinan yang tidak pantas dapat memicu konsekuensi negatif, yang mungkin lebih meningkatkan kepekaan dan kerentanan terhadap kesalahpahaman yang dapat menyebabkan disfungsi organisasi seperti penurunan kinerja, absensi dan turnover tinggi (Lamude, 1994; Motowidlo, 2003). Dengan demikian, pencegahan hasil negatif tersebut penting vis to vis menggunakan gaya kepemimpinan yang berbeda. Ketidakcocokan mungkin mengendapkan lingkaran setan tak berujung dan berpotensi mengganggu bahwa banyak pemimpin organisasi ingin menghindari dan karena itu, mereka mungkin ingin untuk mengatasi gaya mereka dan konsekuensi petugas lebih ketat $^{3}$.

Topik OCB saat ini terus mendorong minat para peneliti dan praktisi. Menurut Ackfeldt dan Coote (2005), hal itu disebabkan oleh hasil penelitian, munculnya keinginan untuk melakukan penelitian OCB terkait dengan kinerja individu dan organisasi. Hal ini juga relevan dengan apa yang Angadi dan Naik (2011) mengungkapkan bahwa kinerja suatu organisasi merupakan faktor yang kompleks antara faktor-faktor lain yang ditentukan oleh perilaku anggota individu. Secara konseptual, Organ (dalam Foote \& Tang, 2008) menggambarkan OCB sebagai perilaku yang didasarkan pada relawan yang tidak bisa dikenakan pada batas-batas pekerjaan dan tidak akan secara resmi menerima penghargaan tapi mampu memberikan kontribusi kepada organisasi. Dengan kata lain, OCB adalah tindakan karyawan yang dilakukan secara sukarela dan di luar peran mereka yang dapat memberikan kontribusi positif terhadap organisasi. Dalam kehidupan sehari-hari di

\footnotetext{
${ }^{2}$ Lihat Lee Kim Lian; Low Guan Tui. Leadership Styles and Organizational Citizenship Behavior: The Mediating Effect of Subordinates' Competence and Downward Influence Tactics. Journal of Applied Business and Economics. vol. 13(2). 2012 p. 59-96

${ }^{3}$ Lee Kim Lian; Low Guan Tui. Leadership Styles and Organizational Citizenship Behavior: The Mediating Effect of Subordinates' Competence and Downward Influence Tactics. Journal of Applied Business and Economics. vol. 13(2). 2012 p. 59-96
} 
organisasi, menurut Organ, dalam Tschannen-Moran, (2003) OCB muncul dalam bentuk altruism, conscientiousness, sportsmanship, courtesy, and civic virtue. ${ }^{4}$

Berdasarkan uraian di atas, artikel ini akan mengeksplorasi bagaimana gaya kepemimpinan dapat mempengaruhi organizational citizenship behavior (OCB) karyawan. Tujuan yang ingin dicapai dalam penulisan artikel ini adalah untuk mengkaji beberapa penelitian empiris yang menghubungkan antara gaya kepemimpinan dan $O C B$.

\section{Literatur Review}

\subsection{Kepemimpinan}

Kepemimpinan didefinisikan sebagai kemampuan untuk mempengaruhi orang lain untuk menyelesaikan sesuatu. Ini mencerminkan perilaku hubungan antara pemimpin dan pengikut dalam situasi tertentu dengan tujuan umum untuk mencapai hasil akhir organisasi. Umumnya, para peneliti menyarankan bahwa kepemimpinan seorang pemimpin yang efektif harus mampu mengartikulasikan visi, menanamkan kepercayaan, keyakinan, kesetiaan dan memimpin bakat karyawan langsung dalam mencapai tujuan organisasi ${ }^{5}$. Kualitas seorang pemimpin dapat menentukan gaya khusus untuk pemimpin, yang dapat menciptakan gambaran positif dari pemimpin di antara bawahan. Opini konstruktif ini, pemimpin dapat memimpin ke arah perubahan positif dalam sikap dan perilaku anggota kelompok, yang pada gilirannya dapat meningkatkan kepuasan kerja dan kinerja bawahan yang efisien (Grosso, 2008) ${ }^{6}$. Bagian berikut secara khusus membahas gaya kepemimpinan transaksional dan transformasional, kharismatik, otoritas, melayani dan etis.

Kepemimpinan transaksional merupakan komponen inti dari perilaku kepemimpinan yang efektif dalam organisasi sebelum pengenalan teori kepemimpinan transformasional (Bass, 1985; Burns, 1978; House, 1977) ${ }^{7}$. Kepemimpinan transaksional didukung oleh teori pertukaran, di mana seorang pemimpin dan bawahan menentukan tujuan dan prosedur untuk mencapai tujuan dengan cara pertukaran imbalan dan penggunaan paksaan untuk memperoleh kepatuhan bawahan dan upaya untuk mencapai kinerja organisasi (Bass, 1985) ${ }^{8}$. Menurut Burn (1978), hubungan pertukaran adalah elemen kunci tercermin dari kepemimpinan transaksional. Pemimpin transaksional menuntut bawahan mereka setuju dengan diterima atau memenuhi permintaan mereka jika bawahan mengharapkan imbalan dan sumber daya atau menghindari tindakan hukuman. Proses pertukaran gaya kepemimpinan telah dikaitkan dengan reward kontingen dan perilaku hukuman dan disebut

\footnotetext{
${ }^{4}$ Benny Hutahayan, Siti Astuti, Kusdi Raharjo Endang, Djamhur Hamid. The Efect Of Transformational Leadership, Organizational Culture, Reward To Organizational Citizenship Of Employee Behavior At Pt Barata Indonesia (Persero). Interdisciplinary Journal Of Contemporary Research In Business. Vol 5, NO 6. Institute of Interdisciplinary Business Research. 2013. P. 466-474.

${ }^{5}$ Lee Kim Lian; Low Guan Tui. Leadership Styles and Organizational Citizenship Behavior: The Mediating Effect of Subordinates' Competence and Downward Influence Tactics. Journal of Applied Business and Economics.vol. 13(2). 2012 p. 59-96

${ }^{6}$ Lihat Muhammad Amin, Saeeda Shah, Ijaz Ahmad Tatlah,. Impact of Principals/Directors' Leadership Styles on Job Satisfaction of the Faculty Members: Perceptions of the Faculty Members in a Public Universityof Punjab, Pakistan. Journal of Research and Reflections in Education.December 2013, Vol.7, No.2, pp $97-112$

${ }^{7}$ Lee Kim Lian; Low Guan Tui. Leadership Styles and Organizational Citizenship Behavior: The Mediating Effect of Subordinates' Competence and Downward Influence Tactics. Journal of Applied Business and Economics.vol. 13(2). 2012 p. 59-96

${ }^{8}$ Lihat Muhammad Amin, Saeeda Shah, Ijaz Ahmad Tatlah,. Impact of Principals/Directors' Leadership Styles on Job Satisfaction of the Faculty Members: Perceptions of the Faculty Members in a Public Universityof Punjab, Pakistan. Journal of Research and Reflections in Education.December 2013, Vol.7, No.2, pp $97-112$
} 
sebagai perilaku pemimpin transaksional (Bryman,1992). Menurut avolio dan Bass, (1988), tipikal manajer pemimpin transaksional cenderung untuk mengidentifikasi kebutuhankaryawan pada tingkat yang lebih rendah dengan menentukan tujuan yang bawahan perlu capai dan berkomunikasi dengan mereka tentang bagaimana keberhasilan pelaksanaan tugas-tugas akan menyebabkan menerima penghargaan pekerjaan yang diinginkan? .

Tiga dimensi yang terkait dengan kepemimpinan transaksional sebagaimana yang dikemukakan oleh Avolio et al., (1995) ${ }^{10}$. Pertama, reward Kontinjensi: Reward kontinjensi adalah proses pertukaran antara pemimpin dan bawahan mereka di mana seorang pemimpin dengan persetujuan bawahan memutuskan tujuan, mendefinisikan imbalan untuk pencapaian tujuan dan menyediakan kompensasi yang disepakati ketika tujuan kinerja terpenuhi. Kedua, management-by-exception (aktif): Ini adalah perilaku kepemimpinan di mana pemimpin mengamati kinerja bawahan dengan ketat dan mengambil langkah-langkah perbaikan kesalahan yang diperlukan. Ketiga, management-by-exception (pasif), pemimpin menunggu secara pasif terhadap kesalahan pengikut yang kemudian dipanggil untuk diberikan perhatian sebelum mengambil tindakan korektif dengan umpan balik negatif atau teguran.

Kepemimpinan transformasional, dalam dua dekade terakhir merupakan gaya kepemimpinan yang digembar-gemborkan beberapa sarjana perilaku organisasi mengenai sebuah genre baru dari teori kepemimpinan alternatif. Kepemimpinan transformasional sebagai pemimpin yang kharismatik, dan visioner. Dvir, Dov, Avolio, \& Shamir (2002) mengatakan bahwa pemimpin transformasional memberikan pengaruh tambahan dengan memperluas dan meningkatkan tujuan pengikut mereka dan menyediakan mereka dengan keyakinan untuk melakukan melampaui harapan yang ditentukan dalam perjanjian pertukaran implisit maupun eksplisit. Pemimpin transformasional menunjukkan perilaku karismatik, membangkitkan kekaguman, menginspirasi, memotivasi, memberikan stimulasi intelektual, dan memperlakukan para pengikut mereka dengan pertimbangan individual. Perilaku seperti mengubah pengikut mereka dengan mengilhami mereka untuk mencapai potensi penuh mereka dan menghasilkan tingkat kinerja tertinggi. Pemimpin transformasional mengevaluasi potensi semua pengikut dalam hal kemampuan mereka untuk memenuhi komitmen saat ini sementara juga membayangkan perluasan lebih lanjut dari tanggung jawab mereka ${ }^{11}$. Perilaku kepemimpinan transformasional dikelompokkan menjadi empat dimensi yaitu, pertama, Pengaruh individual. Pengaruh Individual terjadi ketika para pemimpin mendapatkan kepercayaan dan rasa hormat dari para pengikut mereka dengan melakukan hal yang benar daripada memastikan bahwa bawahan melakukan hal yang benar. Kedua, Stimulasi intelektual. Stimulasi intelektual mempromosikan kecerdasan, rasionalitas, dan kemampuan pemecahan masalah dengan hati. Hal ini juga melibatkan rasionalitas bawahan, membuat mereka untuk menantang asumsi-asumsi mereka dan berpikir tentang masalah-masalah lama dengan cara baru. Ketiga, pertimbangan Individu. Pertimbangan individu berkaitan dengan memperlakukan karyawan sebagai individu, bukan hanya anggota kelompok. Pemimpin menunjukkan sifat ini dengan menjadi belas kasih, menghargai, dan responsif terhadap

\footnotetext{
${ }^{9}$ Lee Kim Lian; Low Guan Tui. Leadership Styles and Organizational Citizenship Behavior: The Mediating Effect of Subordinates' Competence and Downward Influence Tactics. Journal of Applied Business and Economics.vol. 13(2). 2012 p. 59-96

${ }^{10}$ Lihat Muhammad Amin, Saeeda Shah, Ijaz Ahmad Tatlah,. Impact of Principals/Directors' Leadership Styles on Job Satisfaction of the Faculty Members: Perceptions of the Faculty Members in a Public Universityof Punjab, Pakistan. Journal of Research and Reflections in Education. December 2013, Vol.7, No.2, pp $97-112$

${ }^{11}$ Atika Modassir, Tripti Singh,. Relationship of Emotional Intelligence withTransformational Leadership and OrganizationalCitizenship Behavior. International Journal of Leadership Studies, Vol. 4 Iss. 1, 2008. pp. 3-21
} 
kebutuhan karyawan dan dengan mengakui dan merayakan prestasi mereka. Keempat, Motivasi inspirasional. Pemimpin transformasional menginspirasi pengikut mereka untuk mencapai prestasi besar dengan mengkomunikasikan harapan yang tinggi dengan menggunakan simbol-simbol untuk memfokuskan upaya dan dengan mengungkapkan tujuan penting. Pemimpin transformasional cenderung memperhatikan perbedaan antarindividu antara pengikut mereka dan sering bertindak sebagai mentor bagi bawahan mereka, biasanya pembinaan dan memberikan saran kepada pengikut dengan perhatian pribadi individu ${ }^{12}$.

Kepemimpinan karismatik terkenal sebagai kekuatan pribadi seseorang dianggap luar biasa dan menarik oleh orang lain (Weber, 1947; Turner, 1993). Conger dan Kanungo (1987) mendefinisikan kepemimpinan karismatik sebagai "atribusi yang dibuat oleh pengikut yang mengamati perilaku tertentu pada bagian dari pemimpin dalam konteks organisasi". Perilaku kepemimpinan karismatik termasuk visi dan artikulasi, kepekaan lingkungan, perilaku yang tidak konvensional, mengambil risiko pribadi, kepekaan terhadap kebutuhan anggota, dan tidak mempertahankan status quo (Conger dan Kanungo, 1987, 1994). Shamir et al. (1993) menyatakan bahwa kepemimpinan karismatik memiliki efek dengan sangat melibatkan konsep diri pengikut untuk kepentingan misi yang diartikulasikan oleh pemimpin. Dengan kata lain, efek kepemimpinan karismatik mengubah perilaku pengikut melalui pembuatan penting dari nilai-nilai dan identitas mereka ${ }^{13}$.

Kepemimpinan otoritas. Merupakan bagian dari kepemimpinan paternalistik yaitu gaya yang menggabungkan disiplin yang kuat dan kewenangan dengan kebajikan kebapakan dan integritas moral ditulis dalam suasana kepribadian. Kepemimpinan paternalistik terdiri dari tiga elemen: kepemimpinan otoritas, kepemimpinan kebajikan dan kepemimpinan moral. Sebagaimana yang telah diketahui bahwa kepemimpinan otoritas adalah unsur yang paling jelas dan paling berbeda, terutama di Cina (Wu, 2008). Dari sudut pandang para pemimpin, dapat diverifikasi bahwa perilaku seorang pemimpin dapat menegaskan otoritas mutlak, mengontrol bawahan dan menuntut ketaatan. Perilaku ini, dianggap perlu dipertanyakan oleh bawahan, seperti yang dibahas dalam karya Cheng et al. (2004). Farh dan Cheng (2000) menyarankan bahwa kepemimpinan otoritas berasal dari tradisi budaya Konfusianisme dan Legalisme dan tersebar luas di organisasi bisnis di Cina ${ }^{14}$. Kepemimpinan otoritas menunjukkan bahwa ketegangan para pemimpin dan otoritas mutlaknya perlu dipertanyakan, yang menyebabkan pemimpin mengambil kendali ketat atas bawahan dan menuntut ketaatan penuh dari mereka. Secara umum, perilaku konkret yang mengkarakterisasi kepemimpinan otoritas termasuk kontrol dan dominasi, meremehkan kemampuan bawahan, membangun citra luhur pemimpin dan memerintahkan bawahan dalam gaya didaktik /bersifat mendidik ${ }^{15}$.

Kepemimpinan etis. Kepemimpinan etis bersandar pada dua pilar penting: persepsi pemimpin sebagai orang yang bermoral dan sebagai manajer yang bermoral (Trevino et. al.,

12 Bass dan Avolio (1993) dalam Atika Modassir, Tripti Singh. Relationship of Emotional Intelligence withTransformational Leadership and OrganizationalCitizenship Behavior. International Journal of Leadership Studies, Vol. 4 Iss. 1, 2008. pp. 3-21

13 Anyi Chung, I-Heng Chen, Amber Yun-Ping Lee, Hsien Chun Chen and Yingtzu Lin. Charismatic leadershipand self-leadershipA relationship of substitutionor supplementation in the contextsof internalization and identification? Journal of Organizational Change Management. Vol. 24 No. 3 , 2011. pp. 299-313

${ }^{14}$ Ning Hongyu, Zhou Mingjian, Lu Qiang and Wen Liqun. Exploring relationship between authority leadership and organizational citizenship behavior in China The role of collectivism. Chinese Management Studies. Vol. 6 No. 2 Emerald Group Publishing Limited : 2012). pp. 231-244

${ }^{15}$ Cheng, 1995 dalam Ning Hongyu, Zhou Mingjian, Lu Qiang and Wen Liqun. Exploring relationship between authority leadership and organizational citizenship behavior in China The role of collectivism. Chinese Management Studies. Vol. 6 No. 2 Emerald Group Publishing Limited: 2012. pp. 231244 
2000.). Kemudian, Brown, Trevino, dan Harrison (2005) mendefinisikan kepemimpinan etis sebagai demonstrasi perilaku normatif yang tepat melalui tindakan pribadi dan hubungan interpersonal, dan promosi perilaku tersebut kepada pengikut melalui komunikasi dua arah, penguatan, dan pengambilan keputusan. Pemimpin etis fokus pada nilai-nilai moral dan keadilan dalam semua keputusan mereka, mempertimbangkan dampak dari keputusan organisasi pada pihak eksternal dan jelas menyampaikan kepada karyawan bagaimana tindakan mereka di tempat kerja berkontribusi pada tujuan keseluruhan organisasi ${ }^{16}$.

Kepemipinan melayani. Greenleaf (1970) mendefinisikan kepemimpinan yang melayani sebagai filsafat altruistik praktis yang mendukung orang-orang yang memilih untuk melayani terlebih dahulu, dan kemudian memimpin sebagai cara memperluas pelayanan kepada individu dan lembaga. Kepemimpinan melayani mendorong kolaborasi, kepercayaan, pandangan ke depan, mendengarkan, dan penggunaan etika kekuasaan dan pemberdayaan. Kepemimpinan yang melayani sangat cocok untuk organisasi pengetahuan didorong karena pendekatan pekerja berpusat dan berorientasi pada pertumbuhannya ${ }^{17}$. Sebuah ajaran sentral dari teori kepemimpinan yang melayani menurut Joseph \& Winston, (2005) adalah menempatkan kepentingan pengikut di atas kepentingan pribadi. Stone et al. (2004) mengemukakan bahwa - motif pengaruh pemimpin yang melayani bukanlah untuk mengarahkan orang lain melainkan untuk memotivasi dan memfasilitasi pelayanan dan pengelolaan oleh para pengikut ${ }^{18}$.

\subsection{Organizational Citizenship Behavior $(O C B)$}

Salah satu topik yang paling banyak dipelajari dalam penelitian perilaku organisasi dalam beberapa tahun terakhir adalah Organizational Citizenship Behavior (OCB). Konsep tersebut dikenalkan oleh Bateman \& Organ pada 1980-an dan yang terakhir disempurnakan dan diperkuat oleh sejumlah peneliti seperti Podsakoff dan Mackenzie et.al, Jahangir et al, dan Rasgar, et.al., dan yang lainnya. Konsep OCB pada kenyataannya bahwa OCB memberikan kontribusi terhadap meningkatkan efektivitas organisasi. Efektivitas organisasi akan meningkat ketika karyawan bekerja melampaui panggilan tugas dan bahkan membantu sesama pekerja dalam rangka mencapai tujuan organisasi. Organ mendefinisikan OCB sebagai perilaku yang diskresioner, tidak secara langsung atau eksplisit diakui oleh sistem reward formal dan yang secara agregat meningkatkan fungsi efektif organisasi. Menurut Schnake (1991), perilaku etika pro-sosial seperti membantu karyawan baru untuk memahami cara kerja internal organisasi, membantu rekan kerja menyelesaikan pekerjaan mereka, menghadiri pertemuan dan secara sukarela melakukan hal-hal lebih dari resep pekerjaan. perilaku ini merupakan perilaku yang dapat dikaitkan dengan $\mathrm{OCB}^{19}$.

OCB adalah istilah yang mencakup sesuatu yang positif dan konstruktif yang dilakukan karyawan, keputusan mereka sendiri, yang mendukung rekan kerja dan menguntungkan perusahaan. Biasanya, karyawan yang sering terlibat dalam OCB mungkin tidak selalu menjadi top performer, tetapi mereka adalah orang-orang yang diketahui bekerja

\footnotetext{
${ }^{16}$ R.F. Piccolo, R. Greenbaum, D.N. Den Hartog, \& R. Folger, R. The relationship between ethical leadership and core job characteristics. Journal of Organizational Behavior, 2010. 31, 259-278.

${ }^{17}$ M.C. De Sousa, \& D. Van Dierendonck, Knowledge workers, servant leadership andthe search for meaning in knowledge-driven organizations. The Horizon, 18(3), (2010) 230-239.

18 Michelle Vondey. The Relationships among Servant Leadership, Organizational Citizenship Behavior, Person-Organization Fit, and Organizational Identification. International Journal of Leadership Studies, Vol. 6 Iss. 1, (2010). p. 4-27
}

19 Abbas Ali Rastgar, Azim Zarei, Sayed Mehdi Mousavi Davoudi, Kiarash Fartash. The link between workplace spirituality, Organizational citizenship behavior and job Performance in iran. A Journal of Economics and Management. Vol.1 Issue 6, September. (2012). p. 51-67. 
ekstra atau bekerja di atas dan di luar upaya minimum yang diperlukan untuk melakukan pekerjaan yang hanya memuaskan. Organisasi akan mendapatkan keuntungan dari dorongan karyawan untuk terlibat dalam OCB, karena telah terbukti meningkatkan produktivitas, efisiensi dan kepuasan pelanggan, dan mengurangi biaya dan tingkat turnover dan ketidakhadiran $^{20}$. Meskipun OCB adalah inisiatif spontan yang diambil oleh staf, OCB dapat dipromosikan di tempat kerja melalui motivasi karyawan, serta memberi mereka kesempatan untuk menampilkan OCB; yaitu menciptakan lingkungan kerja yang tidak hanya memungkinkan dilakukannya, tapi keadaan kondusif yang dapat mendukung OCB. Karena itu manajemen harus dididik tentang OCB, dan mempertimbangkan memiliki OCB termasuk dalam evaluasi kinerja dalam rangka untuk secara aktif mendorong di antara karyawan.

Para peneliti memiliki pandangan yang berbeda terhadap dimensi dari OCB. Organ (1988), menempatkan lima dimensi OCB yaitu: altruisme (altruism), kesopanan (courtesy), kesadaran (conscientiousness), kebajiakn warga (civic virtue), dan sportivitas (sportsmanship). Smith, et.al., (1983) mengkonsepkan OCB ke dalam dua dimensi yaitu, altruisme dan kepatuhan umum (altruism and generalized compliance). Selanjutnya, Organ (1990) memasukkan dua dimensi tambahan: peacekeeping and cheerleading. Graham (1991) dalam studinya, tiga dimensi OCB yaitu ketaatan organisasi, komitmen organisasi dan partisipasi organisasi (organizational obedience, organization commitment and organization participation). Berdasarkan lima dimensi taksonomi Organ (1988), Williams dan Anderson (1991) mengusulkan konsep dua dimensi OCB: OCB-I (perilaku diarahkan individu, yang terdiri dari altruisme dan kesopanan) dan OCB-II (perilaku diarahkan organisasi, yang terdiri dari sisa tiga dimensi yaitu kesadaran, sportivitas dan civic virtue yang di konseptualisasikan Organ,1988). Oplatka (2006), mengusulkan tujuh dimensi OCB yaitu membantu, sportivitas, loyalitas organisasi, kepatuhan organisasi, inisiatif individu, civic virtue dan pengembangan diri $^{21}$. Namun dimensi yang umumnya dibahas oleh para peneliti adalah lima dimensi oleh organ, 1988, seperti yang digunakan Padsakoff, et.al., (1990), yaitu: Altruisme, Conscientiousness, Sportivitas, civic virtue dan Courtesy. Altruism menunjukkan perilaku yang langsung ditujukan untuk membantu beberapa orang tertentu. conscientiousness menunjukkan perilaku yang memberikan peran jauh melampaui tingkat minimum yang diperlukan. Sportsmanship menunjukkan perilaku yang terlibat ketika seseorang menerima frustrasi tanpa keluhan. Courtesy menunjukkan perilaku mengambil tindakan untuk mencegah masalah dari yang diperoleh dengan menghormati keinginan dan hasrat orang lain. Civic Virtue menujukkan perilaku perilaku yang dirancang untuk meningkatkan partisipasi seseorang dan dukungan dari organisasi secara keseluruhan ${ }^{22}$.

Pentingnya OCB telah diakui sebagai faktor kunci terhadap kinerja organisasi. Diketahui bahwa organisasi dengan tingkat OCB yang lebih tinggi menyebabkan berkurangnya absensi, mengurangi turnover, kepuasan dan loyalitas karyawan (Chughtai dan Zafar, 2006; Khalid dan Ali, 2005; Meyer et al, 1997;. Podaskoff dan Mackenzie , 1997) yang pada akhirnya dapat peningkatan kinerja organisasi. Literatur OCB menunjukkan bahawa dimensi OCB memiliki dampak terhadap kinerja organisasi, namun dapat juga dikritik atas dasar bahwa kontributor yang berbeda telah menganalisis lebih independen

\footnotetext{
${ }^{20}$ Nathan P. Podsakoff, Steven W. Whiting, and Philip M. Podsakoff, \& Brian D. Blume. Individual and Organizational-Level Consequences of Organizational Citizenship Behaviors: A Meta-Analysis. Journal of Applied Psychology.Vol. 94, No. 1, (2009). 122-141.

${ }^{21}$ Hardeep Chahal and Shivani. Antecedents and consequences of Organisational Citizenship Behaviour (OCB): a conceptual framework in reference to health care sector. Journal of Services Research. 10.2 (Oct. 2010): p25.

22 Omid Rashvand dan Elham Bahrevar. A Study of the Relationship among Spiritual intelligence, Organizational Citizenship Behavior and Turnover Intentions. International Journal of Research in Organizational Behavior and Human Resource Management, Vol. 1, No. 2. (2013), pp. 25-34.
} 
dampak dimensi OCB terhadap kinerja organisasi. Dampak OCB pada efektivitas/kinerja organisasi dapat diteliti berdasarkan parameter seperti mengurangi absensi, mengurangi turnover, kepuasan karyawan, loyalitas karyawan, retensi karyawan, loyalitas pelanggan dan kepuasan pelanggan ${ }^{23}$

Bentuk-bentuk konsekuensi dari OCB adalah pertama, mengurangi absensi, berbagai penelitian menemukan bahwa organisasi dengan tingkat OCB yang lebih tinggi menyebabkan penurunan absensi. Kedua, mengurangi turnover: Chughtai dan Zafar (2006); Khalid dan Ali (2005); Meyer et. al. (1997); Podsakoff dan Mackenzie (1997) berpendapat bahwa tingkat OCB yang lebih tinggi dalam organisasi memberikan kontribusi untuk mengurangi niat turnover. Ketiga, retensi karyawan. Meyer et. al. (2007); Podsakoff dan Mackenzie (1997) mencerminkan bahwa dimensi OCB seperti altruism dan sportivitas dapat meningkatkan kinerja organisasi dengan meningkatkan kemampuan organisasi untuk menarik dan mempertahankan orang-orang terbaik. Keempat, kepuasan karyawan. Berbagai penelitian seperti Chughtai dan Zafar (2006); Khalid dan Ali (2005) menemukan bahwa dimensi OCB seperti altruisme dan kesadaran dapat meningkatkan kepuasan karyawan dalam organisasi. Kelima, kepuasan konsumen: Sivadas dan Baker (2000) dan Kersnik (2001), kepuasan konsumen sebagai faktor penting untuk meningkatkan kinerja organisasi. Peningkatan kualitas berkelanjutan untuk memberikan kepuasan konsumen yang berkelanjutan telah menjadi komponen penting dari penilaian kualitas. Keenam, loyalitas konsumen: Ruyter dan Bloemer (1999) dan Gallarza dan Saura (2004) mengidentifikasi bahwa efektivitas organisasi dapat lebih lanjut, diperiksa melalui ukuran sesuai dengan kebutuhan konsumen lain yang dikenal sebagai kesetiaan konsumen ${ }^{24}$.

\section{Hubungan Kepemimpinan dengan OCB : Studi Empirik}

Beberapa penelitian yang terkait dengan pengaruh gaya kepemimpinan terhadap organizational citizenship behavior $(O C B)$ secara empirik terbukti berpengaruh positif. Seperti studi Changquan, et, at., (2011) menemukan bahwa kepemimpinan yang efektif dapat memberikan kontribusi kuat pada pengembangan dari persepsi instrumentalitas organisasi dan individu, dan menyebabkan OCB yang lebih besar ${ }^{25}$. Zacher \& Jimmieson, (2013) menemukan bahwa kepemimpinan transformasional berhubungan positif dengan OCB dan produktivitas penjualan ${ }^{26}$. Muhdar at al (2015) menunjukkan bahwa kepemimpinan yang baik mendorong terbentuknya OCB dalam suatu organisasi ${ }^{27}$. Babcock-Roberson dan Strickland (2010) menemkan bahwa hubungan positif yang signifikan antara kepemimpinan

\footnotetext{
${ }^{23}$ Hardeep Chahal and Shivani Metha. Antecedents and consequences of Organisational Citizenship Behaviour (OCB): a conceptual framework in reference to health care sector. Journal of Services Research. 10.2 (Oct. 2010): p25.

${ }^{24}$ Hardeep Chahal and Shivani Metha. Antecedents and consequences of Organisational Citizenship Behaviour (OCB): a conceptual framework in reference to health care sector. Journal of Services Research. 10.2 (Oct. 2010): p25.

${ }^{25}$ Changquan Jiao, David A, Richards, Kai Zhang. Leadership and Organizational Citizenship Behavior: OCB-Specific Meanings as Mediators. J Bus Psychol. (2011). p. 11-25

${ }^{26}$ Hannes Zacher and Nerina L. Jimmieson, Leader-follower interactions: relations with OCB and sales productivity. Journal of Managerial Psychology. Vol. 28 No. 1, (2013) pp. 92-106.

27 Muhdar HM, Mahlia Muis, Ria Mardiana Yusuf, dan Nurjannah Hamid. The Influence of Spiritual Intelligence, Leadership, and Organizational Culture on Organizational Citizenship Behavior and Employees Performance (A Study on Islamic Banks in Makassar, South Sulawesi Province, Indonesia), The International Journal Of Business \& Management. Vol 3 Issue 1. January, 2015 p. $297-314$
} 
kharismatik dan keterlibatan kerja, antara keterlibatan kerja dan OCB, dan antara kepemimpinan kharismatik dan $\mathrm{OCB}^{28}$

Ning Hongyu, et, al., (2012) menemukan bahwa pada tingkat individu, kepemimpinan otoritas berpengaruh positif dengan OCB. Dan juga berpengaruh ketika dimediasi kolektivisme. Pada tingkat tim: kepemimpinan otoritas berpengaruh positif dengan OCB Tim melalui mediasi kolektivisme tim. Semakin tinggi kolektivisme, semakin kuat hubungan positif antara kepemimpinan otoritas dan $\mathrm{OCB}^{29}$. Rose Su-Jung Lin, et, al., (2012) menemukan bahwa kepemimpinan transformasional memiliki hubungan positif yang signifikan dengan pemberdayaan dan OCB. Pemberdayaan secara signifikan berhubungan dengan $\mathrm{OCB}^{30}$. Saeed \& Ahmad (2012) menemukan bahwa kepemimpinan transformasional dan OCB berkorelasi positif. Studi ini menunjukkan bahwa pemimpin transformasional mendorong altruisme, kesopanan dan kesadaran pada bawahan ${ }^{31}$. Maharani, et, al., (2013) menemukan bahwa servant leadership berpengaruh signifikan terhadap Budaya Organisasi, Komitmen Organisasi, dan Kinerja karyawan, tetapi tidak pada OCB; Budaya Organisasi berpengaruh terhadap OCB dan kinerja karyawan secara signifikan; Pengaruh Komitmen Organisasi terhadap OCB secara signifikan, tetapi tidak pada Kinerja Karyawan; Pengaruh OCB terhadap Kinerja Karyawan signifikan ${ }^{32}$. Xiaojun Lu (2014) menemukan bahwa kepemimpinan etis memiliki pengaruh yang signifikan pada OCBO dan $\mathrm{OCBI}^{33}$. Vondey, (2010) menemukan bahwa perilakukepemimpinan yang melayanimemprediksiOCB karyawan danbahwaorang-organisasi yang baik dan identifikasiorganisasi memediasi hubungan antarakepemimpinan yang melayani dengan $\mathrm{OCB}^{34}$.

\subsection{Kepemimpinan Transformasional dengan OCB}

Kepemimpinan transformasional berhubungan positif dengan OCB. Sebuah penjelasan yang mungkin untuk diharapkan adalah bahwa karakteristik pengikut berhubungan positif dengan kepemimpin transformasional dan menginternalisasi keyakinan, nilai-nilai, dan perilaku normatif mereka. Dengan demikian, mereka memprioritaskan kepentingan kolektif dengan mengorbankan kepentingan pribadi dan menerima pujian dan pengakuan yang mengarah pada peningkatan motivasi dan loyalitas kepada pemimpin mereka (Wang et al., 2005). Pentingnya kepemimpinan transformasional untuk OCB

${ }^{28}$ Babcock-Roberson, Elaine, Meredith; dan Strickland, Oriel J. (2010). The Relationship Between Charismatic Leadership, Work Engagement, and Organizational Citizenship Behaviors. The Journal of Psychology, Taylor \& Francis Group, 144 (3) p. 313-326.

29 Ning Hongyu, Zhou Mingjian, Lu Qiang and Wen Liqun. Exploring relationship between authority leadership and organizational citizenship behavior in China The role of collectivism. Chinese Management Studies. Vol. 6 No. 2 (2012). pp. 231-244

${ }^{30}$ Rose Su-Jung Lin, Hung-Hui Li and Jui-Kuo Hsiao. What are the Relationships Between Transformational Leadershipand Organizational Citizenship Behavior?-An Empirical Study. International Conference on Economics, Business Innovation.IACSIT Press, Singapore, (2012) p. 170-174

${ }^{31}$ Amir Saeed, Shahbaz Ahmad. Perceived Transformational Leadership Style and Organizational Citizenship Behavior: A Case Study of Administrative Staff of University of the Punjab. European Journal of Business and Management. Vol 4, No.21. (2012)_p. 150-158

${ }^{32}$ Vivin Maharani, Eka Afnan Troena, \& Noermijati. Organizational Citizenship Behavior Role in Mediating the Effect of Transformational Leadership, Job Satisfaction on EmployeePerformance: Studies in PT Bank Syariah Mandiri Malang East Java. International Journal of Business and Management; Vol. 8, No. 17, (2013) p 1-12.

${ }^{33}$ Xiaojun Lu. Ethical Leadership And Organizational Citizenship Behavior: The Mediating Roles Of Cognitive And Affective Trust. Social Behavior And Personality. Society for Personality Research. 42(3), (2014). p. 379-390.

34 Michelle Vondey, The Relationships among Servant Leadership, Organizational Citizenship Behavior, Person-Organization Fit, and Organizational Identification. International Journal of Leadership Studies, Vol. 6 Iss. 1, (2010) p. 4-27 
didokumentasikan dengan baik dalam literatur. Sebagai contoh, Podsakoff et al. (1996) menemukan hubungan positif antara kepemimpinan transformasional dan OCB dalam sebuah studi dari 1.539 bawahan dan 1.200 manajer dari berbagai industri mengalami kecocokan dengan OCB. Sebuah studi manufaktur dan layanan pelanggan menunjukkan bahwa kepemimpinan transformasional berhubungan positif dengan tingkat OCB supervisi ${ }^{35}$

Ketika pemimpin transformasional memberikan pengaruh, pengikut menginternalisasi nilai-nilai organisasi dan pemimpin, menerima visi lebih baik sehingga mereka tidak hanya melakukan untuk keperluan penghargaan ekstrinsik atau kepatuhan, tetapi mereka benarbenar mengubah sikap, keyakinan, dan nilai-nilai mereka. Proses ini menurut Piccolo dan Colquitt (2006) melibatkan pergeseran dari tujuan pribadi ke tujuan-tujuan kolektif, dari identitas pribadi dengan identitas kolektif, dari kepentingan diri sendiri untuk kepentingan kolektif, dan telah diusulkan sebagai dasar untuk kemampuan pemimpin transformasional untuk mendorong $\mathrm{OCB}^{36}$. Kepemimpinan transformasional dan OCB. Dalam studi sebelumnya telah menemukan hubungan langsung antara kepemimpinan transformasional dan OCB. Podsakoff, Mackenzie, dan Bommer mencatat bahwa pengaruhkepemimpinan transformasional pada OCB mungkin lebih penting daripada pengaruh pada in-role behavior. Secara umum, perilaku kepemimpinan transformasional memiliki hubungan positif yang signifikan dan konsisten dengan 5-dimensi OCB. Secara bersama-sama, ini menunjukkan bahwa kepemimpinan transformasional memiliki sejumlah pengaruh penting pada $\mathrm{OCB}^{37}$

\subsection{Kepemimpinan Transaksional dengan OCB}

Rubin et. al., 2010; dan Walumbwa et. al., 2008 menemukan hubungan yang signifikan antara kontingen-reward / kepemimpinan transaksional dan OCB. Demikian pula, menurut Bensimon (1989), pemimpin transaksional yang baik selalu memiliki proses dua arah, pertukaran dan pengaruh timbal balik antara pengikut. Pernyataan konklusif dari studi Riaz dan Haider (2010) menyatakan bahwa kepemimpinan transaksional secara positif berhubungan dengan penghargaan karyawan atas kinerja yang baik dan memberikan pengakuan atas kontribusinya dalam keberhasilan. Bass dan Riggio (2006) menyatakan bahwa pemimpin transaksional cenderung mengarah melalui pertukaran sosial (misalnya, imbalan keuangan, subsidi untuk sumbangan kampanye), dan pekerjaan untuk meningkatkan $\mathrm{OCB}^{38}$. Hubungan positif antara kepemimpinan kontingen-reward dan OCB karyawan telah didokumentasikan dengan baik (Podsakoff etal. 2000). Kontingen-Reward melibatkan klarifikasi harapan sekitar kinerja karyawan dan imbalan apa yang karyawan akan terima untuk mencapai tingkat kinerja yang diharapkan (Avolio etal. 1999). Ketika karyawan percaya bahwa perilaku ini akan dihargai, utilitas OCB sebagai sarana untuk mencapai imbalan tersebut meningkat, dan perilaku kontingen-reward oleh pemimpin secara natural berfungsi untuk mempromosikan persepsi instrumentalitas individu pada OCB. Dengan

\footnotetext{
${ }^{35}$ Purvanova dan Bono, 2006 dalam Hannes Zacher and Nerina L. Jimmieson, Leader-follower interactions: relations with OCB and sales productivity. Journal of Managerial Psychology. Vol. 28 No. 1, (2013). pp. 92-106

${ }^{36}$ Changquan Jiao, David A, Richards, Kai Zhang. Leadership and Organizational Citizenship Behavior: OCB-Specific Meanings as Mediators. J Bus Psychol. (2011). p. 11-25.

${ }^{37}$ Rose Su-Jung Lin, Hung-Hui Li and Jui-Kuo Hsiao. What are the Relationships Between Transformational Leadershipand Organizational Citizenship Behavior?-An Empirical Study. International Conference on Economics, Business Innovation.IACSIT Press, Singapore, (2012). p. 170-174
}

38 Naveed R Khan, Arsalan Mujahid Ghouri, Marinah Awang, Leadership Styles And Organizational Citizenship Behavior In Small And Medium Scale Firms. International Refereed Research Journal. Vol.- IV, Issue - 2. (2013). 
demikian, diharapkan bahwa instrumentalitas individu yang dimiliki oleh karyawan memediasi dampak kepemimpinan kontingen-reward pada OCB karyawan ${ }^{39}$

\subsection{Kepemimpinan Kharismatik dengan OCB}

Howell dan Frost (1989) menemukan hubungan positif antara kepemimpinan kharismatik dan kinerja organisasi. Hasil dari penelitian lain juga menunjukkan bahwa kepemimpinan kharismatik memiliki dampak positif yang signifikan terhadap $\mathrm{OCB}^{40}$. Shamir et. al., (1993) mengidentifikasi bahwa, pengikut yang terinspirasi oleh gaya kepemimpinan kharismatik mampu mencapai hasil yang mengejutkan dengan memberikan pengertian, identifikasi dan pemahaman dengan tujuan organisasi. Studi empiris dari Sosik (2005) membangun dan memverifikasi bahwa kepemimpinan kharismatik berpengaruh positif dengan OCB pengikut. Sebuah penelitian terbaru telah meneliti hubungan antara kharisma dan dua dimensi OCB: membantu dan kepatuhan (Den Hartog, et,al., 2007). Hasil penelitian menunjukkan bahwa karyawan menampilkan lebih banyak membantu dan kepatuhan ketika mereka melihat pemimpinnya berkarismatik ${ }^{41}$.

\subsection{Kepemimpinan Otoritas (authority leadership) dengan OCB}

Dalam pekerjaan, OCB didasarkan pada pola yang diusulkan oleh Williams dan Anderson yang menganggap dan hubungan antara kepemimpinan otoritas (authority leadership) dengan OCB dalam konteks kepemimpinan Cina. Ia berpendapat bahwa kepemimpinan otoritas secara positif berhubungan dengan OCB. Ada dua mekanisme di mana kepemimpinan otoritas dapat meningkatkan OCB. Pertama, kepemimpinan otoritas juga termasuk dalam anteseden OCB dapat diandalkan, yang berarti bahwa kepemimpinan otoritas dapat menyebabkan ketaatan, hormat dari bawahan kepada atasan. Dengan mengaktifkan kepemimpinan otoritas, seperti membantu perilaku, loyalitas organisasi dan kepatuhan organisasi, dapat dilihat bahwa kepemimpinan otoritas akan meningkatkan OCB bawahan. Kedua, kepemimpinan otoritas meliputi manajemen otoriter dan manajemen otoritatif. Manajemen otoriter sebagai bagian yang tergantung pada kontrol dan eksploitasi yang unggul, misalnya bawahan dapat menunjukkan kesesuaian dan ketergantungan untuk menerima imbalan atau menghindari hukuman. Manajemen otoritatif juga ditentukan oleh kontrol, sementara alasan yang mendasari itu adalah untuk mempromosikan kesejahteraan karyawan $^{42}$

\subsection{Hubungan Kepemimpinan Etis (Ethical Leadership) dan OCB}

Para peneliti telah menekankan peran positif dari kepemimpinan etis dalam OCB karyawan berdasarkan interaksi pertukaran sosial (Kacmar, Andrews, Harris, \& Tepper, 2013). Sebagai indikator, OCB dapat digunakan untuk menguji validitas kepemimpinan etis. Menurut Williams dan Anderson (1991), dua aspek mendasari konstruk OCB: diarahkan pada organisasional (OCBO), di mana anggota berkontribusi terhadap produktivitas organisasi secara keseluruhan dan mematuhi aturan-aturan informal yang dirancang untuk menjaga

39 Changquan Jiao, David A, Richards, Kai Zhang. Leadership and Organizational Citizenship Behavior: OCB-Specific Meanings as Mediators. J Bus Psychol. (2011). p. 11-25.

${ }^{40}$ Lee Kim Lian; Low Guan Tui. Leadership Styles and Organizational Citizenship Behavior: The Mediating Effect of Subordinates' Competence and Downward Influence Tactics. Journal of Applied Business and Economics.vol. 13(2). (2012). p. 59-96

${ }^{41}$ Babcock-Roberson, Elaine, Meredith; dan Strickland, Oriel J. (2010). The Relationship Between Charismatic Leadership, Work Engagement, and Organizational Citizenship Behaviors. The Journal of Psychology, Taylor \& Francis Group, 144 (3) p. 313-326

42 Ning Hongyu, Zhou Mingjian, Lu Qiang and Wen Liqun. Exploring relationship between authority leadership and organizational citizenship behavior in China The role of collectivism. Chinese Management Studies. Vol. 6 No. 2 (2012). pp. 231-244. 
ketertiban organisasi; dan diarahkan secara individual (OCBI), di mana para anggota secara tidak langsung berkontribusi terhadap organisasi melalui perilaku membantu yang mencakup informasi dan berbagi tugas ${ }^{43}$.

\subsection{Kepemimpinan Melayani (Servent leadership) dan OCB}

Perilaku kerjaatau dikenal sebagai OCB dalam organisasi yang berkomitmen untuk meningkatkan kualitas pelayanan juga sangat penting untuk dikembangkan atau dipelihara. Northouse, (2001), kepemimpinan melayani sebagai dasar kepemimpinan yang efektif dan pemimpin harus mendukung kompetensi karyawan untuk mewujudkan kinerja terbaik, bertanggung jawab pada operasi organisasi ${ }^{44}$. Ajaran sentral dari teori kepemimpinan y melayani adalah menempatkan kepentingan pengikut di atas kepentingan pribadi (Joseph \& Winston, 2005). Kepemimpinan yang melayani mungkin lebih kondusif untuk OCB karena fokus pada pengembangan pengikut, membangun komunitas, kepemimpinan otentik, dan kepemimpinan berbagi (Graham, 1991; Laub, 2003; Sendjaya et al, 2008.). Winston (2003) mengusulkan bahwa pelayanan pemimpin kepada pengikut mengakibatkan layanan timbal balik antara pengikut dan pemimpin. Stone et al. (2004) mengemukakan bahwa - motif pengaruh pemimpin melayani bukanlah untuk mengarahkan orang lain melainkan untuk memotivasi dan memfasilitasi pelayanan dan pengelolaan oleh para pengikut. Layanan pengikut kepada orang lain dan pengelolaan sumber daya organisasi dapat ditafsirkan sebagai $\mathrm{OCB}^{45}$

\section{Penutup: Simpulan, Implikasi, dan Rekomendasi}

Simpulan: OCB adalah sebuah konsep yang mendapat perhatian oleh para akademisi dan praktisi, karena kedudukannya yang mampu menstimulasi efektivitas kerja organisasi. Salah satu variabel yang dapat berperan mempengaruhi OCB karyawan adalah gaya kepemimpinan. Studi literatur yang dilakukan menunjukan bahwa gaya kepemimpinan seperti kepemimpinan transformasional, transaksional, kharismatik, otoritas, dan kepemimpinan yang melayani secara empirik terbukti berpengaruh positif terhadap perilaku OCB karyawan. Artinya semakin efektif kepemimpinan perusahaan maka semakin baik OCB karyawan, akibatnya efektivitas dan produktivitas organisasi juga akan tercapai. Namun kesimpulan itu tidak berlaku ketika mengacu pada temuan Maharani, et al (2013) yang menemukan kepemimpinan transformasional dan kepemimpinan melayani (Harwiki, 2013) tidak signifikan pengaruhnya pada OCB. Perbedaan dari dua temuan tersebut menandakan bahwa kepemimpinan khususnya kepemimpinan transformasional dan melayani relatif masih menimbulkan perdebatan diantara peneliti.

Implikasi: perbedaan temuan beberapa peneliti, khususnya kepemimpinan transformasional dan melayani terhadap OCB, antara signifikan dan tidak signifikan menyebabkan perlunya dilakukan penelitian dalam cakupan yang lebih luas dalam rangka untuk membantu mengkaji fenomena tersebut dalam tingkatan organisai yang lain, agar dapat

\footnotetext{
${ }^{43}$ Xiaojun Lu. Ethical Leadership And Organizational Citizenship Behavior: The Mediating Roles Of Cognitive And Affective Trust. Social Behavior And Personality. Society for Personality Research. 42(3), (2014). p. 379-390.

${ }^{44}$ Wiwiek Harwiki. The Influence of Servant Leadership on Organization Culture, Organizational Commitment, Organizational Citizenship Behavior and Employees' Performance (Study of Outstanding Cooperatives in East Java Province, Indonesia). Journal of Economics and Behavioral Studies. Vol. 5, No. 12. (2013). . pp. 876-885

45 Michelle Vondey. The Relationships among Servant Leadership, Organizational Citizenship Behavior, Person-Organization Fit, and Organizational Identification. International Journal of Leadership Studies, Vol. 6 Iss. 1, (2010). p. 4-27
} 
memperoleh gambaran yang lebih komprehensif tentang perkembangan kontribusi peran variabel kepemimpinan transformasional dan melayani terhadap OCB.

Rekomendasi, kepada manajer harus memberikan contoh perilaku yang lebih nyata bagi karyawan untuk melayani pelanggan yang lebih baik, untuk membantu orang lain, dan menciptakan kegiatan tepat untuk menjaga komitmen karyawan dan melahirkan OCB karyawan yang terberdayakan. Kepada peneliti/akademisi melakukan pengujian perbedaan OCB berdasarkan jenis kelamin, pendidikan, masa kerja dan data lainnya, sehingga penelitian yang dilakukan dilebih luas dan detail.

\section{REFERENSI}

Amin, Muhammad; Shah, Saeeda; Tatlah, Ahmad, Ijaz. (2013). Impact of Principals/Directors' Leadership Styles on Job Satisfaction of the Faculty Members: Perceptions of the Faculty Members in a Public Universityof Punjab, Pakistan. Journal of Research and Reflections in Education.December 2013, Vol.7, No.2, pp $97-112$

Anyi Chung, I-Heng Chen, Amber Yun-Ping Lee,Hsien Chun Chen and Yingtzu Lin. (2011).Charismatic leadershipand self-leadershipA relationship of substitutionor supplementation in the contextsof internalization and identification?Journal of Organizational Change Management.Vol. 24 No. 3, pp. 299-313

Babcock-Roberson, Elaine, Meredith; dan Strickland, Oriel J. (2010). The Relationship Between Charismatic Leadership, Work Engagement, and Organizational Citizenship Behaviors. The Journal of Psychology, Taylor \& Francis Group, 144 (3) p. 313-326.

Budiyanto and Oetomo; Widi; Hening. (2011). The Effect of Job Motivation, Work Environment and Leadership on Organizational Citizenship Behavior, Job Satisfaction and Public Service Quality in Magetan, East Java, Indonesia. World Academy of Science, Engineering and Technology. Vol:51. p. 159 -167.

Chahal, Hardeep and Mehta, Shivani. (2010). Antecedents and consequences of Organisational Citizenship Behaviour (OCB): a conceptual framework in reference to health care sector. Journal of Services Research. 10.2 (Oct. 2010): p25.

Changquan Jiao, David A, Richards , Kai Zhang. (2011). Leadership and Organizational Citizenship Behavior: OCB-Specific Meanings as Mediators. J Bus Psychol. p. $11-25$.

De Sousa, M. C., \& Van Dierendonck, D. (2010). Knowledge workers, servant leadership andthe search for meaning in knowledge-driven organizations. The Horizon, $18(3), 230-239$.

HM, Muhdar; Muis, Mahlia; Yusuf, R. Mardiana; dan Hamid, Nurjannah. The Influence of Spiritual Intelligence, Leadership, and Organizational Culture on Organizational Citizenship Behavior and Employees Performance (A Study on Islamic Banks in Makassar, South Sulawesi Province, Indonesia), The International Journal of Business \& Management. Vol 3 Issue 1. January, 2015 p. 297 - 314 
Harwiki, Wiwiek.(2013). The Influence of Servant Leadership on Organization Culture, Organizational Commitment, Organizational Citizenship Behavior and Employees' Performance (Study of Outstanding Cooperatives in East Java Province, Indonesia). Journal of Economics and Behavioral Studies. Vol. 5, No. 12. . pp. 876-885

Hutahayan, Benny; Astuti, Siti, Endang;Raharjo, Kusdi; Hamid, Djamhur. (2013). The Efect Of Transformational Leadership, Organizational Culture, Reward To Organizational Citizenship Of Employee Behavior At Pt Barata Indonesia (Persero). Interdisciplinary Journal Of Contemporary Research In Business. Vol 5, NO 6. Institute of Interdisciplinary Business Research. P. 466-474.

Khan, Naveed R; Ghouri,Mujahid, Arsalan; Awang, Marinah. (2013). Leadership Styles And Organizational Citizenship Behavior In Small And Medium Scale Firms. International Refereed Research Journal. Vol.- IV, Issue - 2.

Lee Kim Lian; Low Guan Tui. (2012). Leadership Styles and Organizational Citizenship Behavior: The Mediating Effect of Subordinates' Competence and Downward Influence Tactics. Journal of Applied Business and Economics.vol. 13(2). p. 5996

Maharani,Vivin; Troena, Afnan, Eka;\& Noermijati. (2013). Organizational Citizenship Behavior Role in Mediating the Effect of Transformational Leadership, Job Satisfaction on EmployeePerformance: Studies in PT Bank Syariah Mandiri Malang East Java. International Journal of Business and Management; Vol. 8, No. 17,p 1-12.

Modassir, Atika; Singh, Tripti. (2008). Relationship of Emotional Intelligence withTransformational Leadership and OrganizationalCitizenship Behavior. International Journal of Leadership Studies, Vol. 4 Iss. 1, pp. 3-21

Ning Hongyu, Zhou Mingjian, Lu Qiang and Wen Liqun. (2012). Exploring relationship between authority leadership and organizational citizenship behavior in China The role of collectivism. Chinese Management Studies. Vol. 6 No. 2 Emerald Group Publishing Limited : 2012). pp. 231-244

Piccolo, R. F., Greenbaum, R., Den Hartog, D. N., \& Folger, R. (2010). The relationship between ethical leadership and core job characteristics. Journal of Organizational Behavior, 31, 259-278.

Podsakoff, Nathan P.; Whiting, Steven W. and Podsakoff, Philip M. \& Blume, Brian D. (2009). Individual and Organizational-Level Consequences of Organizational Citizenship Behaviors: A Meta-Analysis. Journal of Applied Psychology.Vol. 94, No. 1, 122-141.

Rashvand, Omid; Bahrevar, Elham. (2013). A Study of the Relationship among Spiritual intelligence, Organizational Citizenship Behavior and Turnover Intentions. International Journal of Research in Organizational Behavior and Human Resource Management, Vol. 1, No. 2, pp. 25-34. 
Rastgar, Ali, Abbas; Zarei, Azim; Davoudi, Mousavi, Mehdi, Seyed; Fartash, Kiarash. (2012). The link between workplace spirituality, Organizational citizenship behavior and job Performance in iran. A Journal of Economics and Management. Vol.1 Issue 6, September. p. 51-67.

Rose Su-Jung Lin, Hung-Hui Li and Jui-Kuo Hsiao. (2012). What are the Relationships Between Transformational Leadershipand Organizational Citizenship Behavior?-An Empirical Study. International Conference on Economics, Business Innovation.IACSIT Press, Singapore, p. 170-174

Saeed,Aamir; Ahmad, Shahbaz. (2012). Perceived Transformational Leadership Style and Organizational Citizenship Behavior: A Case Study of Administrative Staff of University of the Punjab. European Journal of Business and Management. Vol 4, No.21. www.iiste.org, p. 150-158

Suliman, Abubakr dan Al Obaidli, Hanan. (2013). Leadership and Organizational Citizenship Behavior (OCB) in The Financial Service Sector The Case Of The UAE. AsiaPacific Journal of Business Administration. Vol. 5 No. 2, Emerald Group Publishing Limited, p. 115-134

Vondey, Michelle. (2010). The Relationships among Servant Leadership, Organizational Citizenship Behavior, Person-Organization Fit, and Organizational Identification. International Journal of Leadership Studies, Vol. 6 Iss. 1, p. 4-27

Xiaojun Lu. (2014). Ethical Leadership And Organizational Citizenship Behavior: The Mediating Roles Of Cognitive And Affective Trust. Social Behavior And Personality. Society for Personality Research. 42(3),. p. 379-390.

Zacher, Hannes; and Jimmieson, Nerina L. (2013). Leader-follower interactions: relations with OCB and sales productivity. Journal of Managerial Psychology. Vol. 28 No. 1, Emerald Group Publishing Limited. pp. 92-106. 